\title{
Auditory object feature maps with a hierarchical network of independent components?
}

\author{
Jean Rouat*, Simon Brodeur, Éric Plourde \\ From The Twenty Third Annual Computational Neuroscience Meeting: CNS*2014 \\ Québec City, Canada. 26-31 July 2014
}

Auditory Object representation in the brain is still a controversial question [1,2]. Kumar et al. [3] discuss the hierarchical organization for auditory object perception and observe that the Planum Temporale (PT) area of the cortex encodes invariant representations of the spectral envelops of sounds. Many other studies find maps of representations elsewhere in the brain (Cochlear
Nucleus, Inferior Nucleus, etc.). Sparse representations with minimum overlap could be considered, according to Barlow [4]. Griffiths and Warren [5] propose that auditory object representations might be segmented or segregated in the Planum Temporal (PT) by increasing the independence between the neural activities. We therefore explore the potential of a hierarchical neural

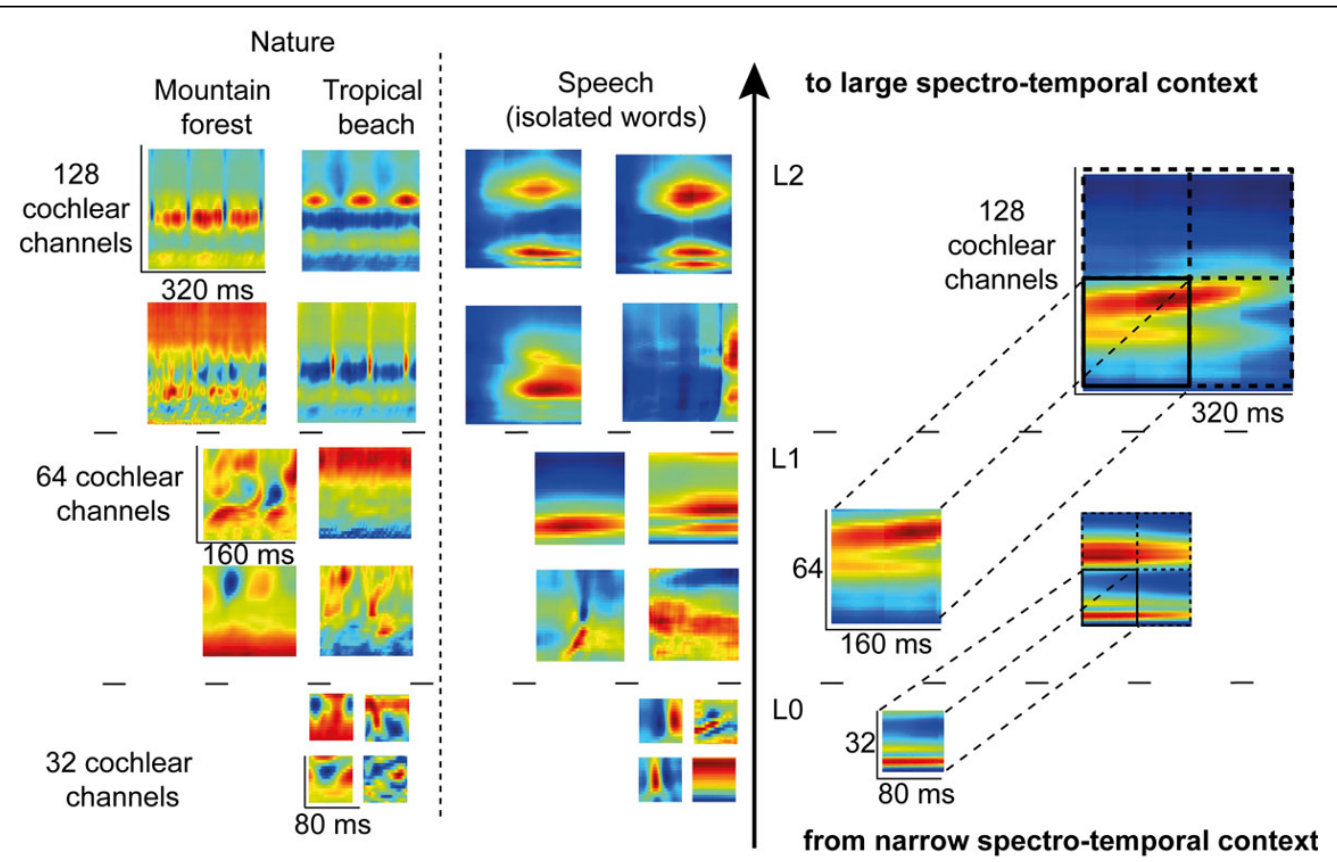

Figure 1 Learned representations illustrated for speech and natural sounds. FastICA training is first done on patches of $80 \mathrm{~ms} \times 32$ cochlear channels of the envelopes coming from a 128 channels cochleagram (Level LO). Then, patches of $160 \mathrm{~ms} \times 64$ cochlear channels are created at level $\mathrm{L} 1$ with a concatenation through time and space of the learned LO features. FastICA is then performed on these larger patches to generate the new $L 1$ representations. The same procedure is repeated for level L2.

*Correspondence: jean.rouat@usherbrooke.ca

NECOTIS, Département génie électrique, génie informatique, Université de Sherbrooke, Québec, Canada, J1K 2R1 
assembly - with the use of a computer simulation whose layers increase the feature independence during training, to represent auditory object parts. It is observed that learned features are organized into nonoverlapping maps (Figure 1) and that redundancy of the representation is in fact reduced. Learning was done on three categories of sounds having distinct acoustical statistics: speech, music and natural sounds. We observed that the learned feature maps are very different from one sound category to another and might be, to some extend, comparable to receptive fields measured in the brain. We discuss of their potential similarity with receptive fields measured in the Inferior Colliculus of the Guinea Pig and how they might be part of a representation of auditory objects in the brain.

Published: 21 July 2014

\section{References}

1. Bizley JK, Cohen YE: The what, where and how of auditory-object perception. Nat Rev. Neuro 2013, 14(10):693-707.

2. Griffiths TD, Warren JD: What is an auditory object? Nat Rev Neurosci 2004 5(887):892.

3. Kumar S, Stephan KE, Warren JD, Friston KJ, Griffiths TD: Hierarchical processing of auditory objects in humans. PLoS Comput Biol, Public Library of Science, 2007, 3(6):e100-e100.

4. Barlow H: Redundancy reduction revisited. Network : Comput. Neural Syst 2001, 12:241-253.

5. Griffiths TD, Warren JD: The planum temporale as a computational hub. Trends in neurosciences 2002, 25(7):348-353.

doi:10.1186/1471-2202-15-S1-P66

Cite this article as: Rouat et al: Auditory object feature maps with a hierarchical network of independent components? BMC Neuroscience 2014 15(Suppl 1):P66.

\section{Submit your next manuscript to BioMed Central} and take full advantage of:

- Convenient online submission

- Thorough peer review

- No space constraints or color figure charges

- Immediate publication on acceptance

- Inclusion in PubMed, CAS, Scopus and Google Scholar

- Research which is freely available for redistribution

Submit your manuscript at www.biomedcentral.com/submit
C Biomed Central 